\section{Inovação em Micro e Pequenas Empresas: Recursos e Capacidades}

\author{
Innovation in Micro and Small Enterprises: Resources and Capabilities
}

\section{RESUMO}

Objetivo: o artigo buscou identificar os recursos relevantes para composição das capacidades gerencial e comercial no contexto das micro e pequenas empresas (MPEs). Método: por meio de uma revisão da literatura, foram identificados os recursos associados à inovação: liderança, gerenciamento de pessoas, informaçóes e conhecimentos, relacionamento com clientes, fornecedores e sociedades, e resultados. Os recursos foram coletados e mensurados por meio de um questionário estruturado disponibilizado pelo programa Agente Local de Inovação, aplicado a 447 MPEs do estado de Pernambuco, entre 2015 e 2017 . Utilizou-se análise fatorial confirmatória para verificar como esses recursos contribuem para composiçáo das capacidades. Resultados: verificou-se que a capacidade gerencial é composta pelo relacionamento com a sociedade e fornecedores, a liderança, o compartilhamento de informaçóes e conhecimentos, e o gerenciamento de pessoas. A capacidade comercial é composta pelo relacionamento com os clientes e os resultados obtidos pela firma. Conclusóes: apesar de as MPEs contarem com restriçóes ao acesso de tecnologias, seus recursos organizacionais parecem contribuir para o desenvolvimento da capacidade de inovação e para obtenção de vantagem competitiva.

Palavras-chave: inovação; capacidades dinâmicas; teoria dos recursos; micro e pequenas empresas.
Renata Braga B. de Vasconcelos $1 \odot$ Joséte Florencio dos Santos' 10 Jackeline Amantino de Andrade ${ }^{\oplus}$

1. Universidade Federal de Pernambuco, Centro de Ciências Sociais Aplicadas, Recife, PE, Brasil.

Como citar: Vasconcelos, R. B. B. de, Santos, J. F. dos, \& Andrade, J. A. de. (2021). Inovação em micro e pequenas empresas: Recursos e capacidades. Revista de Administração Contemporânea, 25(2), el90106. https://doi.org/10.1590/1982-7849rac2021190106.por

\section{ABSTRACT}

Objective: the article aims to identify the relevant resources for the composition of managerial and transactional capabilities in the context of micro and small enterprises (MSEs). Method: through a literature review, the resources associated with the innovation were identified: leadership, people management, information and knowledge, relationships with clients, suppliers, and society, and results. The resources were collected and measured using a structured questionnaire made available by the Local Agent for Innovation program, applied to 447 MSEs in the state of Pernambuco, between 2015 and 2017. Confirmatory factor analysis was used to verify how these resources contribute to the composition of capabilities. Results: the results demonstrate that the managerial capability is composed of the relationship with society and suppliers, leadership, the sharing of information and knowledge, and people management. Transactional capability is made up of the relationship with customers and the results obtained by the firm. Conclusions: although MSEs have restrictions on access to technologies, their organizational resources seem to contribute to the development of innovation capability and to obtain competitive advantage.

Keywords: innovation; dynamic capabilities; resource theory; micro and small enterprises.

\# de revisores convidados até a decisão:

\begin{tabular}{|c|c|c|c|c|c|c|c|c|c|}
\hline & 1 & 2 & 3 & 4 & 5 & 6 & 7 & 8 & 9 \\
\hline $1^{a}$ rodada & (x) & (x) & (x) & $x$ & $\stackrel{\phi}{2}$ & $\stackrel{\phi}{2}$ & & & \\
\hline $2^{\circ}$ rodada & & & & & & & & & \\
\hline $3^{a}$ rodada & & & & & & & & & \\
\hline $4^{\mathrm{a}}$ rodada & & & & & & & & & \\
\hline $5^{\mathrm{a}}$ rodada & 1 & & & & & & & & \\
\hline
\end{tabular}




\section{INTRODUÇÃO}

A inovação pode ser compreendida como impulsionadora do desempenho econômico de setores produtivos, que conduz ao desenvolvimento econômico das naçóes por meio de um processo de destruição criadora (Schumpeter, 1984, 1988). Para tanto, a tecnologia e o acesso a recursos financeiros são fundamentais para inovar (Schumpeter, 1984; Pavitt, 1984).

Por outro lado, Nelson e Winter (1982) compreendem a inovação como uma capacidade essencial e dinâmica das firmas para sua competitividade, entendida como as rotinas, capacidades, habilidades e experiências necessárias para inovar. Assim, ainda que a tecnologia seja importante, ela não é suficiente para promover a inovaçáo, pois é resultado de um processo complexo que depende de um conjunto de recursos e habilidades (Teece, 2007).

Nesta perspectiva, tem-se procurado compreender como a capacidade de inovação se desenvolve (Lawson $\&$ Samson, 2001; Raghuvanshi, Ghosh, \& Agrawal, 2019; Zawislak, Alves, Tello-Gamarra, Barbieux, \& Reichert, 2012). Apesar de não haver um consenso sobre sua operacionalização (Iddris, 2019), os estudos demonstram que a tecnologia é relevante; porém, a gestáo organizacional também assume um importante papel. Zawislak, Alves, TelloGamarra, Barbieux e Reichert (2012), por exemplo, sugerem que a capacidade de inovação pode ser compreendida pelas capacidades tecnológicas e operacionais, mas também pelas capacidades gerenciais e comerciais.

Contudo, além da carência de evidências empíricas, a ênfase dos estudos está nas grandes organizaçôes, que contam com uma estrutura de gestão superior e facilidades no acesso a tecnologias e economias de escala. As micro e pequenas empresas (MPEs), por outro lado, enfrentam limitaçôes financeiras e estruturais, que se tornam entraves para desenvolver inovaçóes (Kim, Park, \& Paik, 2018; Laforet \& Tann, 2006).

Como sugere Saunilla (2019), os estudos sobre a capacidade de inovação, muitas vezes, negligenciam o contexto das pequenas organizaçóes. E, diante de suas restrições e peculiaridades, emerge a necessidade de redefinir o construto 'capacidade de inovação' e identificar os recursos acessíveis e relevantes ao seu contexto. Ainda que, diante das restrições tecnológicas, Zawislak et al. (2012) e Zawislak, Fracasso e Tello-Gamarra (2018) ressaltem a relevância das capacidades gerencial e comercial para as pequenas empresas, não se identifica recursos pertinentes às MPEs que possam contribuir com estas habilidades.

Por outro lado, os estudos que partem da visão baseada em recursos (VBR) se propóem a analisar determinantes da inovação, identificando recursos que contribuem para o desenvolvimento da atividade, inclusive no contexto das pequenas empresas. Le e Lei (2019) e Martínez-Román e Romero (2017) ressaltam que a liderança e o compartilhamento de ideias podem auxiliar a promoção da inovaçáo. Iddris (2019), por sua vez, destaca o relacionamento com clientes e fornecedores. Contudo, os estudos sáo dispersos e incompletos, limitando-se a analisar a relaçáo entre a inovação e uma perspectiva da gestão organizacional. Ademais, não demonstram como os recursos podem contribuir para a capacidade de inovaçáo e para as habilidades da firma em gerenciar suas atividades e comercializar suas inovaçóes.

Diante das lacunas verificadas nas abordagens, cabe indagar: como as MPEs podem se tornar capazes de inovar? Quais recursos elas podem obter para auxiliar o desenvolvimento da sua capacidade de inovação? Nessa perspectiva, este trabalho tem por objetivo identificar os recursos relevantes para composição das capacidades gerencial e comercial no contexto das MPEs. O estudo apresenta um framework que permite investigar o fenômeno da capacidade de inovaçáo, demonstrando recursos que podem auxiliar as MPEs no gerenciamento e comercialização de novas ideias.

Assim, buscam-se contribuiçóes empíricas e teóricas. Diante das restriçóes tecnológicas, os recursos gerenciais podem se tornar centrais para inovação nas MPEs, apesar de ainda serem vistos como ativos suplementares (Guan \& Ma, 2003; Kim et al., 2018). Busca-se, portanto, suplantar as limitaçóes das MPEs no desenvolvimento de inovaçóes, possibilitando que elas identifiquem habilidades e recursos gerenciais para inovar, e que possam adquiri-los, desenvolvê-los e reconfigurá-los. Permite-se ainda observar as dificuldades e fragilidades no uso desses recursos que podem ser sanadas por políticas de suporte.

Por outro lado, ao fazer um recorte na perspectiva gerencial, o estudo traz a contribuiçáo da VBR (Penrose, 1959) para o estudo das capacidades dinâmicas (Dosi, Freeman, \& Nelson, 1988; Teece, Pisano, \& Shuen, 1997; Teece, 2007), fornecendo um framework que facilita a compreensão de como as capacidades podem ser desenvolvidas.

$\mathrm{Na}$ literatura, verificam-se estudos que partem da teoria dos recursos, e que analisam a relação entre os recursos gerenciais e a inovação (Kamasak, 2015; Kim et al., 2018; Le \& Lei, 2019; Martínez-Román \& Romero, 2017; Vasconcelos \& Oliveira, 2018), porém, não contemplam a análise das capacidades. Diferentemente, procura-se aqui observar como os recursos gerenciais podem efetivamente contribuir para a coordenaçáo das atividades e para a habilidade de comercializar novas ideias, ou seja, para as capacidades gerenciais e comerciais que constituem a capacidade de inovação (Zawislak et al., 2012). 
Para tanto, estrutura-se a pesquisa em mais quatro seções. A seguir, são apresentadas as conceituaçōes teóricas sobre a capacidade de inovação, a capacidade gerencial e comercial, e os recursos gerenciais analisados nesta pesquisa. A terceira seção contempla os procedimentos metodológicos utilizados, e a quarta apresenta os principais resultados encontrados no estudo. As conclusões, limitaçôes e consideraçóes sobre pesquisas futuras são apresentadas na última seção.

\section{REFERENCIAL TEÓRICO}

As capacidades dinâmicas das firmas se referem à habilidade de configurar e reconfigurar as competências internas e externas (Teece et al., 1997; Teece, 2007). Sua relevância está em obter novas formas de vantagem competitiva, por meio de um conjunto de papéis da gestáo estratégica que podem ser modificados diante das necessidades das mudanças ambientais (Teece et al., 1997).

Referem-se, portanto, à capacidade adaptativa de empresas para alcançar e sustentar vantagens competitivas diante de ambientes em constante mutação, marcados pelo dinamismo da globalização e de mudanças tecnológicas, sistêmicas e rápidas (Teece et al., 1997; Teece, 2007).

Mais especificamente, a capacidade de inovação pode ser entendida como a capacidade de transformar continuamente conhecimentos e ideias em novos produtos, processos e sistemas para o benefício da empresa e stakeholders (Lawson \& Samson, 2001). Contudo, não há consenso sobre sua definição e quais habilidades são necessárias para desenvolvê-la.

Visando a obter uma maior compreensão, Zawislak et al. (2012) procuram identificar as capacidades necessárias que possibilitam a inovação, e percebem a capacidade de inovação por meio do processo de aprendizagem tecnológica e rotinas gerenciais e comerciais realizados pela firma.

A capacidade de inovaçáo está relacionada à "capacidade de absorver, adaptar e transformar determinada tecnologia em gerenciamento específico, operaçóes e rotinas de transaçóes que podem levar uma empresa aos lucros schumpeterianos" (Zawislak et al., 2012, p. 23), sendo vista a partir de um conjunto de capacidades guiadas pela tecnologia e pelo negócio, apresentadas na Figura 1.

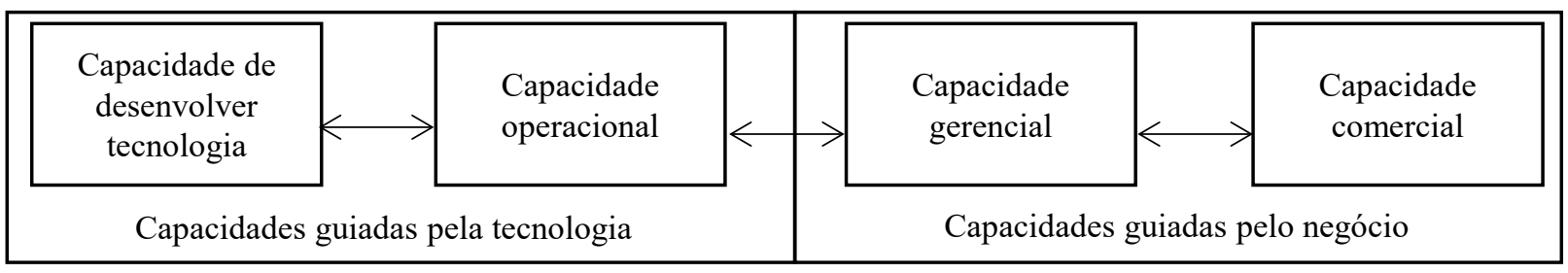

Figura 1. Capacidade de inovação.

Fonte: adaptado de Zawislak, P., Alves, C., Tello-Gamarra, J., Barbieux, D., \& Reichert, F. (2012). Innovation capability: from technology development to transaction capability. Journal of Technology Management \& Innovation, 7(2), 14-27. https://doi.org/10.4067/S0718-27242012000200002

A capacidade guiada pela tecnologia é composta pelas capacidades tecnológica e operacional, que se referem, respectivamente, à capacidade de obter e aplicar novos conhecimentos e soluçóes de mercado, e à capacidade de realizar as operaçóes com qualidade, flexibilidade, baixo custo, prazos de entrega, etc. (Alves, Barbieux, Reichert, Tello-Gamarra, \& Zawislak, 2017). A capacidade guiada pelo negócio é formada pela capacidade gerencial, relacionada à coordenação de recursos e atividades (Alves et al., 2017), e pela capacidade comercial, referente à busca de informaçóes no mercado para reduzir os custos de transação (Coase, 1937; Williamson, 1985).

O framework desenvolvido por Zawislak et al. (2012) propõe que as firmas detêm algum tipo de vantagem de conhecimento, que pode ser traduzida em tecnologia, novos produtos e processos, que podem ser transacionados pela organizaçáo. Para tanto, deve-se possuir rotinas e procedimentos estabelecidos para gerenciar a capacidade de operar esta tecnologia.

Assim, "para que a solução tecnológica possa se traduzir em um arranjo operacional deve ser eficientemente gerenciada para garantir a entrega do resultado esperado" (Zawislak et al., 2012, p. 20), logo, as capacidades gerenciais são pertinentes para transformar a inovação em vantagem competitiva. Ainda que a tecnologia seja operacionalizada, é necessário conectar a empresa ao mercado, através das atividades comerciais de atendimento ao cliente, marketing e logística que orientam mudanças tecnológicas.

Raghuvanshi, Ghosh e Agrawal (2019) apresentam um modelo diferente de Zawislak et al. (2012), porém também destacam a relevância dos aspectos relacionados à gestão organizacional, que constituem os pilares da capacidade. Guan e Ma (2003) também indicam que as 
capacidades tecnológicas não são suficientes para suportar um desempenho superior. Apesar de destacarem os investimentos em pesquisa e desenvolvimento (P\&D) e manufatura para a competitividade das empresas, ressaltam as habilidades organizacionais e estratégicas como ativos suplementares, que possibilitam desempenho sustentável.

Do mesmo modo, Kim et al. (2018) indicam que a habilidade de transformar os investimentos em P\&D em produtos é relevante para a inovação, porém sua capacidade de comercializar e analisar a concorrência influencia a relação entre a inovação e o desempenho da firma. Verifica-se que as capacidades relacionadas à gestão organizacional podem exercer um papel importante na geração de inovaçóes, e tornam-se ainda mais necessárias no contexto das MPEs, diante das dificuldades que enfrentam no acesso à tecnologia (Laforet \& Tann, 2006).

Apesar de suas limitações, as MPEs representam parte significativa da economia de diversos países (Lee \& Newton, 2000). No Brasil, os pequenos negócios representam $98,5 \%$ do total de empresas privadas e são responsáveis por cerca $30 \%$ da produção de riqueza do país e pela geraçáo de $51 \%$ dos empregos (Serviço Brasileiro de Apoio às Micro e Pequenas Empresas [Sebrae], 2020).

São consideradas MPEs as empresas que obtêm receita bruta anual inferior a $\mathrm{R} \$ 4.800 .000,00$ (quatro milhões e oitocentos mil reais) (Lei n. $\left.{ }^{\circ} 155,2016\right)$. Porém, $88 \%$ referem-se a microempresas, cuja receita é inferior a $\mathrm{R} \$ 360.000,00$ (trezentos e sessenta mil reais), e sua maioria é composta por negócios familiares contemplando menos de 10 empregados, sendo voltados principalmente aos segmentos de comércio e serviço (Sebrae, 2020).

Porém, como destacam Laforet e Tann (2006), as MPEs enfrentam dificuldades para acessar tecnologias e capital e obter economias de escala, dificultando as inovaçóes. Contudo, apesar das dificuldades estruturais e tecnológicas, Vasconcelos e Oliveira (2018) demonstram que as MPEs são capazes de inovar em produtos e serviços, nos canais de comunicação e arranjos organizacionais, apoiando-se nas capacidades guiadas pelo negócio.

A compreensão dessas capacidades, porém, exige a análise dos recursos que facilitam seu desenvolvimento. Como sugere Penrose (1959), as firmas são como um feixe de recursos, marcadas pela heterogeneidade em combiná-los e utilizá-los. A teoria de recursos pode auxiliar a compreender como os processos estratégicos e organizacionais podem revelar a capacidade da organizaçáo em responder a mudanças ao alterar sua base de recursos e criar inovaçóes, conforme Eisenhardt e Martin (2000). Afinal, as decisóes organizacionais podem reconfigurar as capacidades de inovação, promovendo novos arranjos que favorecem a manutenção da competitividade (Tometich, Fracasso, Zen, \& Engelman, 2019).

Zawislak et al. (2018), por exemplo, identificam recursos associados às capacidades de inovaçáo orientadas ao negócio. Segundo os autores, a capacidade gerencial está relacionada ao planejamento estratégico, recursos humanos e normas e procedimentos. Já a capacidade comercial é composta pelo relacionamento com o cliente, o poder de barganha e a gestão dos contratos com clientes e fornecedores. Porém, como salientam, a pesquisa apresenta limitaçôes, sugerindo a realização de pesquisas quantitativas que possam ser aplicadas a um número maior de empresas em segmentos específicos.

Por outro lado, Bayarçelik, Tasel e Apak (2014), Karpak e Topcu (2010), Le e Lei (2019), Martínez-Román e Romero (2017) e Vasconcelos e Oliveira (2018) apresentam fatores que contribuem para a capacidade de inovação e a performance inovadora das pequenas empresas, como a liderança, o relacionamento com clientes e a sociedade, a utilização de redes de conhecimento, etc., estabelecendo uma relaçáo direta entre os recursos e a inovação ou a capacidade de inovação.

Contudo, este estudo sugere que a relevância desses recursos para a inovação pode se dar justamente por sua contribuição ao desenvolvimento das capacidades gerenciais e comerciais, o que requer uma análise desses recursos e relaçóes.

\section{Recursos relacionados à capacidade de inovação}

Não existe uma estrutura geralmente aceita para investigar a capacidade de inovação, pois não há consenso na definição e operacionalização desta capacidade (Iddris, 2019). Assim, verificam-se na literatura estudos que abordam diferentes recursos associados à capacidade de inovar (Bayarçelik, Taşel, \& Apak, 2014; Iddris, 2019; Kamasak, 2015; Kim et al., 2018; Le \& Lei, 2019; Rogers, 2004; Silva, Mainardes, Raposo, \& Sousa, 2012; Vasconcelos \& Oliveira, 2018).

De modo geral, tais estudos identificam determinantes para a capacidade da inovaçáo e seu desempenho, utilizando diferentes contextos e abordagens. A revisão desses trabalhos possibilita identificar recursos que podem contribuir para as capacidades guiadas pelo negócio, apresentados na Tabela 1 . 
Tabela 1. Revisão da literatura.

\begin{tabular}{|c|c|c|c|}
\hline Autores & Método & Nível de análise & Principais resultados \\
\hline Rogers (2004) & Regressão probit & Empresas australianas & $\begin{array}{l}\text { Verifica-se associação positiva entre a utilização de networks e a inovação em pequenas } \\
\text { empresas de manufatura. }\end{array}$ \\
\hline $\begin{array}{l}\text { Bos-Brouwers } \\
(2009)\end{array}$ & Estudo de caso & PMEs da Holanda & $\begin{array}{l}\text { A liderança dinâmica e empreendedora favorece a inovação. Sua orientação para } \\
\text { sustentabilidade e para troca de informaçóes promove atividades com potencial } \\
\text { inovador. }\end{array}$ \\
\hline $\begin{array}{l}\text { Karpak e Topcu } \\
(2010)\end{array}$ & ANP & Experts em PMEs & $\begin{array}{l}\text { A personalidade, conhecimentos e habilidades do empreendedor e a regulaçáo e } \\
\text { política do mercado são fatores que contribuem para o sucesso das PMEs. }\end{array}$ \\
\hline Söllner (2010) & Regressão probit & Empresas alemães & Verifica-se associação positiva entre a diversidade do capital humano e a inovação. \\
\hline Laforet (2011) & $\begin{array}{l}\text { Teoria } \\
\text { fundamentada, } \\
\text { entrevistas }\end{array}$ & Gestores de PMEs & $\begin{array}{l}\text { São identificados impulsionadores da inovaçáo, como o ambiente de mercado, } \\
\text { relacionamento com clientes e concorrentes, habilidades gerenciais, resultados } \\
\text { financeiros e crescimento da empresa. }\end{array}$ \\
\hline $\begin{array}{l}\text { Silva, Mainardes, } \\
\text { Raposo e Sousa } \\
(2012)\end{array}$ & Regressão logit & $\begin{array}{l}\text { Empresas portuguesas } \\
\text { do setor de serviços }\end{array}$ & $\begin{array}{l}\text { Investimentos em } \mathrm{P} \& \mathrm{D} \text {, compartilhamento de informaçáo e atividades de marketing } \\
\text { contribuem para inovar. }\end{array}$ \\
\hline $\begin{array}{l}\text { Bayarçelik et al. } \\
(2014)\end{array}$ & AHP & PMEs em Istambul & $\begin{array}{l}\text { As habilidades dos gestores, os aspectos financeiros e a orientação para o mercado } \\
\text { foram considerados relevantes no processo de inovaçáo. }\end{array}$ \\
\hline $\begin{array}{l}\text { El Elj e Abassi } \\
(2014)\end{array}$ & Regressão & $\begin{array}{l}\text { Empresas industriais } \\
\text { do Mediterrâneo }\end{array}$ & $\begin{array}{l}\text { A capacidade de absorção depende do aprendizado e do conhecimento gerados pela } \\
\text { empresa, que contribuem positivamente para a disposiçáo de inovar. }\end{array}$ \\
\hline $\begin{array}{l}\text { Genis-Gruber e } \\
\text { Ögüt (2014) }\end{array}$ & Regressão logit & $\begin{array}{l}\text { Indústria química, } \\
\text { plástico, aço e móveis } \\
\text { da Uniấo Europeia }\end{array}$ & Características dos clientes e fornecedores afetam a motivação para a inovação. \\
\hline $\begin{array}{l}\text { Farace e Mazzotta } \\
(2015)\end{array}$ & Regressão probit & $\begin{array}{l}\text { PMEs de manufatura } \\
\text { do sul da França }\end{array}$ & $\begin{array}{l}\text { O capital humano, o empreendedor e as redes de conhecimento contribuem para a } \\
\text { capacidade de absorçáo, facilitando a inovação. }\end{array}$ \\
\hline Kamasak (2015) & $\begin{array}{l}\text { Análise fatorial e } \\
\text { regressão linear }\end{array}$ & 194 empresas & $\begin{array}{l}\text { O relacionamento com clientes e fornecedores e a cultura de inovação estão } \\
\text { relacionados ao desempenho da inovaçáo. }\end{array}$ \\
\hline $\begin{array}{l}\text { Martínez-Román e } \\
\text { Romero (2017) }\end{array}$ & Regressão linear & PMEs da Espanha & $\begin{array}{l}\text { A motivaçáo do empreendedor, o planejamento do negócio e as redes de conhecimento } \\
\text { são significativos para desenvolver inovaçôes centrais. }\end{array}$ \\
\hline $\begin{array}{l}\text { Kim, Park e Paik } \\
(2018)\end{array}$ & $\begin{array}{l}\text { Análise fatorial } \\
\text { exploratória }\end{array}$ & $\begin{array}{l}\text { PMEs listadas na bolsa } \\
\text { de valores da Coreia do } \\
\text { Norte }\end{array}$ & $\begin{array}{l}\text { A liderança da gestão e a rede de conhecimentos são facilitadores da capacidade de } \\
\text { inovaçáo, contribuindo para a performance das firmas. }\end{array}$ \\
\hline $\begin{array}{l}\text { Vasconcelos e } \\
\text { Oliveira (2018) }\end{array}$ & $\begin{array}{l}\text { Regressão linear e } \\
\text { análise envoltória } \\
\text { de dados }\end{array}$ & MPEs brasileiras & $\begin{array}{l}\text { A liderança, as informaçóes e conhecimentos, o relacionamento com clientes e a } \\
\text { sociedade influenciam positivamente a capacidade de inovaçấo e sua eficiência. }\end{array}$ \\
\hline $\begin{array}{l}\text { Vasconcelos, Vieira } \\
\text { e Silveira }(2020)\end{array}$ & $\begin{array}{l}\text { Regressão em } \\
\text { painel }\end{array}$ & $\begin{array}{l}\text { MPEs do setor } \\
\text { gastronômico }\end{array}$ & $\begin{array}{l}\text { Os processos internos e os resultados alcançados são os principais determinantes da } \\
\text { inovaçáo. }\end{array}$ \\
\hline Iddris (2019) & Estudo de caso & $\begin{array}{l}\text { PMEs de manufaturas } \\
\text { de baixa tecnologia }\end{array}$ & $\begin{array}{l}\text { A colaboraçáo com agentes institucionais, clientes e fornecedores influencia a } \\
\text { capacidade de inovaçáo. }\end{array}$ \\
\hline Le e Lei (2019) & $\begin{array}{l}\text { Análise fatorial } \\
\text { confirmatória }\end{array}$ & $\begin{array}{l}\text { Empresas de } \\
\text { manufatura e serviço } \\
\text { chinesas }\end{array}$ & $\begin{array}{l}\text { A liderança transformadora e o compartilhamento de informação impactam } \\
\text { positivamente a promoçáa de inovaçãa. }\end{array}$ \\
\hline
\end{tabular}

A partir da revisão, é possível observar que os recursos relacionados ao desenvolvimento da inovaçáo ainda são dispersos e incompletos. Isoladamente, cada estudo analisa uma perspectiva da inovação; porém, em conjunto, possibilitam identificar recursos que podem estar associados à capacidade gerencial e comercial.

Por meio desta revisão com o enfoque embasado pela teoria de recursos, identificaram-se sete construtos referentes aos recursos organizacionais, desenvolvendo as hipóteses referentes às capacidades gerencial e comercial. A seguir são apresentados os recursos analisados: (a) liderança; (b) informaçóes e conhecimentos; (c) gerenciamento de pessoas; (d) relacionamento com a sociedade; (e) relacionamento com fornecedores; (f) relacionamento com clientes; (g) resultados.

\section{Liderança}

Os líderes têm um importante papel ao promover mudanças organizacionais e definir projetos organizacionais (Teece, 2007), podendo incentivar e compartilhar informaçóes com seus stakeholders para promover inovaçóes (Vasconcelos, Vieira, \& Silveira, 2020) e engajar pessoas para implementar as mudanças necessárias (Popadiuk, Luz, \& Kretschmer, 2018). Para Iddris (2019), as inovações 
podem surgir da percepção dos empreendedores por meio do aprendizado interativo que mantêm com stakeholders.

Estudos empíricos sugerem que as experiências e conhecimentos das lideranças e seu estilo de gestão promovem inovações em grandes organizações (Le \& Lei, 2019), e em pequenas (Bayarçelik et al., 2014; Karpak \& Topcu, 2010; Kim et al., 2018; Martínez-Román \& Romero, 2017). Para Bayarçelik et al. (2014), o estilo de gestão do líder facilita a obtenção de informaçóes externas e promove a experimentação e o empreendedorismo.

Observa-se que estratégias de gestão praticadas pela liderança, sua busca por conhecimentos e o compartilhamento de informaçôes podem contribuir com o gerenciamento dos recursos e das atividades, ou seja, com a capacidade gerencial, propondo-se a seguinte hipótese:

$\mathrm{H}_{1}$. A capacidade gerencial está relacionada positivamente com a liderança.

\section{Informações e conhecimentos}

O estabelecimento de networks e o compartilhamento de conhecimentos entre empresas possibilitam adotar estratégias mais eficazes que melhoram o desempenho inovador (Kamasak, 2015; Laforet, 2011; Le \& Lei, 2019). Ainda que seus efeitos possam variar segundo o tamanho e o setor da empresa (Rogers, 2004), a absorção de informaçóes e conhecimentos pode conduzir a inovaçóes radicais e sustentáveis (Bos-Brouwers, 2009).

Estudos empíricos com PMEs, realizados por Farace e Mazzotta (2015), Kim et al. (2018) e Martínez-Román e Romero (2017), indicam que as redes de conhecimento contribuem positivamente para a capacidade de inovação, possibilitando acessar novos conhecimentos que podem ser utilizados na reavaliação dos processos. Os estudos sugerem que o compartilhamento de informaçóes com os stakeholders pode contribuir para o desenvolvimento de processos, atividades e rotinas, de modo que se espera uma relação positiva com a capacidade gerencial.

$\mathrm{H}_{2}$. A capacidade gerencial está relacionada positivamente com as informaçóes e conhecimentos compartilhados pela empresa.

\section{Gerenciamento de pessoas}

Farace e Mazzotta (2015), Laforet (2011) e Söllner (2010) destacam que a capacidade de inovação também depende das habilidades dos funcionários. Assim, a construção do ambiente propício à inovação deve começar pelo processo de recrutamento de máo de obra e incluir treinamentos e capacitaçóes que estimulem a autonomia da equipe.
Söllner (2010) destaca que a diversidade do capital humano, de idades, de gêneros e de educação possibilita construir um ambiente criativo que estimula a geração de ideias. Já rigidez na definição e execução das tarefas pode reduzir este potencial (Vasconcelos \& Oliveira, 2018).

Verifica-se que as práticas relacionadas à gestão de pessoas tendem a auxiliar a coordenação das atividades e dos recursos, e contribuir para a capacidade gerencial, facilitando o desenvolvimento de inovações.

$\mathrm{H}_{3}$. A capacidade gerencial está relacionada positivamente com o gerenciamento de pessoas.

\section{Relacionamento com a sociedade}

De acordo com Karpak e Topcu (2010), as regulações e políticas criam condições para a prosperidade e desenvolvimento de inovaçóes. Nidumolu, Prahalad e Rangaswami (2009) e Vasconcelos e Oliveira (2018) destacam que as políticas e regulaçóes, sejam econômicas, sejam sociais ou ambientais, podem estimular as atividades nas firmas, instigando-as a buscar soluçóes criativas e a se tornarem proativas diante das determinaçóes do setor.

Assim, o atendimento às exigências legais, sociais e ambientais pode permitir que a empresa conheça seu ambiente e reavalie suas atividades e processos para adequálos às necessidades e imposiçóes, contribuindo com a capacidade gerencial.

$\mathrm{H}_{4}$. A capacidade gerencial está relacionada positivamente com o relacionamento com a sociedade.

\section{Relacionamento com fornecedores}

Kamasak (2015) salienta que a proximidade com fornecedores permite que as empresas obtenham acesso a novas ideias que podem se tornar vantagens frente aos concorrentes, destacando a relação de parceria com os fornecedores.

Iddris (2019), inclusive, sugere que a inovação nas pequenas empresas é viabilizada pela colaboração com fornecedores de máquinas, equipamentos e insumos, que também auxiliam fornecendo capacitações e treinamentos necessários. Zawislak et al. (2018), por outro lado, destacam a habilidade da firma de influenciar os termos e as condiçôes do contrato, obtendo vantagens comerciais por meio do poder de barganha.

De maneira geral, os estudos indicam que o relacionamento com fornecedores pode facilitar a comercialização e reduzir o custo de transaçáo associado à capacidade comercial.

$\mathrm{H}_{5}$. A capacidade comercial está relacionada positivamente com o relacionamento com o fornecedor. 


\section{Relacionamento com clientes}

A colaboração e a integração com os clientes podem impulsionar a inovaçáo (Genis-Gruber \& Ögŭüt, 2014; Kamasak, 2015; Laforet, 2011). Kamasak (2015) vê o conhecimento do cliente como impulsionador da inovação, sugerindo o envolvimento ativo dos clientes para obter sucesso nas inovaçóes.

Segundo Bayarçelik et al. (2014), a proximidade das pequenas empresas com seus clientes e o mercado é um dos recursos centrais neste processo, pois novos produtos podem surgir das demandas específicas dos clientes ou de novas condiçóes do mercado. Assim, percebe-se sua relaçáo com a capacidade comercial, visto que os esforços em compreender as necessidades dos clientes e do mercado para desenvolver produtos podem facilitar sua comercialização.

$\mathrm{H}_{6}$. A capacidade comercial está relacionada positivamente com o relacionamento com clientes.

\section{Resultados}

Bayarçelik et al. (2014), Laforet (2011) e Vasconcelos et al. (2020) verificam associação entre a performance da firma e as inovaçôes. Além de o aspecto financeiro ser necessário para desenvolver e operar a inovação (Bayarçelik et al., 2014), as perspectivas de lucratividade e crescimento atuam como impulsionadores da inovaçáo (Laforet, 2011). Tais estudos são condizentes com a perspectiva de Schumpeter (1988), que coloca o crédito como condição necessária para inovar.

Vasconcelos et al. (2020) destacam a relevância dos resultados não financeiros, que também representam o retorno pelo esforço de venda. Assim, espera-se que a capacidade comercial apresente uma relaçáo positiva com os resultados, visto que possibilitam a redução dos custos de transação.

$\mathrm{H}_{7}$. A capacidade comercial está relacionada positivamente com os resultados obtidos.

Como se vê, o desenvolvimento das capacidades orientadas ao negócio pode ocorrer por meio do desenvolvimento dos recursos observados. Para tanto, faz-se necessário verificar as relaçôes estabelecidas. Porém, apesar da classificação teórica, as capacidades estão intimamente relacionadas e contribuem de maneira conjunta para o desenvolvimento da inovação (Zawislak et al., 2012), por isso, espera-se que as capacidades também apresentem relaçóes positivas entre si.

$\mathrm{H}_{8}$. As capacidades gerencial e comercial estão positivamente relacionadas entre si.

\section{PROCEDIMENTOS METODOLÓGICOS}

Esta é uma pesquisa exploratória, que busca obter maior compreensão do fenômeno a ser estudado, e utiliza uma abordagem quantitativa com dados transversais. Para alcançar o objetivo central, tomou-se como população as MPEs participantes do programa Agente Local de Inovação (ALI) do Sebrae, localizadas em Pernambuco entre 2015 e 2017. Consideraram-se MPEs aquelas organizaçóes enquadradas na lei n. ${ }^{\circ} 155$ (Lei n. ${ }^{\circ}$ 155, 2016).

Das 2.838 empresas participantes do programa, selecionou-se, aleatoriamente, uma amostra de 447 empresas, proporcionando erro de $4,25 \%$ e nível de confiança de 95\%. Para seleção, priorizaram-se os segmentos com maior quantitativo de empresas: gastronomia, panificação, indústria de móveis, confecção, vestuário, materiais de construção e hotelaria e turismo. A amostra é composta por empresas de segmentos tradicionais, pouco intensivas em tecnologia.

Os dados da pesquisa foram obtidos de forma secundária por meio do acesso, concedido pelo Sebrae, à base de dados do programa ALI, que utiliza um instrumento de coleta para realizar o diagnóstico empresarial. $O$ questionário utilizado pelo ALI é composto por 37 questóes, aplicado ao empresário ou dirigente da MPE para avaliar a gestão organizacional. Neste estudo, foram consideradas apenas questóes que refletiam os recursos contemplados, totalizando 32 perguntas.

Estudos conduzidos por Vasconcelos e Oliveira (2018) e Vasconcelos et al. (2020) também utilizaram parcialmente o questionário na avaliação dos recursos organizacionais, validando o instrumento de coleta. Para que as açóes de intervenção realizadas pelo ALI não afetassem os resultados, os dados coletados se referem ao diagnóstico inicial realizado antes da efetiva participação das empresas no programa. A Tabela 2 apresenta os aspectos avaliados em cada recurso e os estudos relacionados à formação dos construtos.

Cada aspecto analisado se refere a uma pergunta do questionário, avaliada por meio de uma escala de 0 a 3 pontos, indicando desde a ausência da utilização do recurso (zero) até sua adoção consistente e formalizada (três). Os recursos foram mensurados por meio de um índice, obtido pelo somatório das pontuaçóes registradas nas respectivas questóes dividido pela pontuação máxima do construto. Dada a estratégia de coleta dos dados, não foram obtidos missing values na amostra e a análise dos resíduos padronizados não indicou a presença de outliers. 
Tabela 2. Recursos internos referentes à gestão organizacional.

\begin{tabular}{|c|c|c|}
\hline Recursos observados & Aspectos analisados & Estudos relacionados \\
\hline $\begin{array}{l}\text { Liderança } \\
\text { (Liderança) }\end{array}$ & $\begin{array}{l}\text { Definição da missão } \\
\text { Incentivo ao comportamento ético } \\
\text { Análise de desempenho pelas lideranças } \\
\text { Compartilhamento de informações pelas lideranças } \\
\text { Busca por oportunidades de inovação }\end{array}$ & $\begin{array}{l}\text { Bayarçelik et al. (2014), Bos-Brouwers (2009), Kim et al. (2018), } \\
\text { Laforet (2011), Le e Lei (2019), Martínez-Román e Romero } \\
\text { (2017), Vasconcelos e Oliveira (2018). }\end{array}$ \\
\hline $\begin{array}{l}\text { Informações e } \\
\text { conhecimentos } \\
\text { (Informaçóes) }\end{array}$ & $\begin{array}{l}\text { Definição e disponibilidade das informaçóes para tomada de } \\
\text { decisão } \\
\text { Incentivo ao compartilhamento do conhecimento } \\
\text { Uso de informações para promover melhorias } \\
\text { Obtenção e uso de informaçóes comparativas }\end{array}$ & $\begin{array}{l}\text { Bos-Brouwers (2009), El Elj e Abassi (2014), Kamasak (2015), } \\
\text { Kim et al. (2018), Laforet (2011), Le e Lei (2019), Martínez- } \\
\text { Román e Romero (2017), Rogers (2004), Silva et al. (2012), } \\
\text { Vasconcelos e Oliveira (2018). }\end{array}$ \\
\hline $\begin{array}{l}\text { Gerenciamento de } \\
\text { pessoas } \\
\text { (Pessoas) }\end{array}$ & $\begin{array}{l}\text { Definição das funçôes e responsabilidade } \\
\text { Seleção de colaboradores } \\
\text { Capacitaçáo dos colaboradores } \\
\text { Identificação de perigos e riscos ao trabalho } \\
\text { Promoção do bem-estar e satisfaçáo }\end{array}$ & Farace e Mazzotta (2015), Söllner (2010). \\
\hline $\begin{array}{l}\text { Relacionamento } \\
\text { com a sociedade } \\
\text { (Sociedade) }\end{array}$ & $\begin{array}{l}\text { Conhecimento das exigências legais } \\
\text { Mitigação dos impactos ambientais } \\
\text { Desenvolvimento de projetos sociais }\end{array}$ & $\begin{array}{l}\text { Bos-Brouwers (2009), Karpak e Topcu (2010), Laforet e Tann } \\
\text { (2006), Vasconcelos e Oliveira (2018). }\end{array}$ \\
\hline $\begin{array}{l}\text { Relacionamento } \\
\text { com fornecedores } \\
\text { (Fornecedores) }\end{array}$ & $\begin{array}{l}\text { Seleção e avaliação dos fornecedores } \\
\text { Padronização dos processos } \\
\text { Controle dos processos }\end{array}$ & $\begin{array}{l}\text { Genis-Gruber e Öğüt (2014), Iddris (2019), Kamasak (2015), } \\
\text { Vasconcelos et al. (2020). }\end{array}$ \\
\hline $\begin{array}{l}\text { Relacionamento } \\
\text { com clientes } \\
\text { (Clientes) }\end{array}$ & $\begin{array}{l}\text { Identificação das expectativas dos clientes } \\
\text { Divulgaçáo de produtos e serviços } \\
\text { Registro e tratamento das reclamaçóes } \\
\text { Avaliação da satisfação } \\
\text { Uso das informaçôes dos clientes para tomada de decisão }\end{array}$ & $\begin{array}{l}\text { Bayarçelik et al. (2014), Genis-Gruber e Öğüt (2014), Iddris } \\
\text { (2019), Kamasak (2015), Laforet (2011), Silva et al. (2012), } \\
\text { Vasconcelos e Oliveira (2018). }\end{array}$ \\
\hline $\begin{array}{l}\text { Resultados } \\
\text { (Resultados) }\end{array}$ & $\begin{array}{l}\text { Resultados das satisfações e reclamações dos clientes } \\
\text { Resultados das capacitaçóes dos colaboradores } \\
\text { Resultados da produtividade do trabalho } \\
\text { Resultados referentes à margem de lucro }\end{array}$ & Bayarçelik et al. (2014), Laforet (2011), Vasconcelos et al. (2020). \\
\hline
\end{tabular}

Nota. A tabela apresenta os construtos referentes aos recursos organizacionais. Os aspectos avaliados se referem às questóes formuladas para composição do construto, avaliados por meio de uma escala de 0 a 3 pontos. Os estudos relacionados indicam a literatura utilizada para subsidiar a formulação do construto.

\section{Análise fatorial confirmatória}

Para alcançar o objetivo proposto no artigo, utilizou-se a análise fatorial confirmatória (AFC), que permite verificar como a variável latente é composta pelo conjunto de variáveis observadas a partir da análise das relaçóes estabelecidas. Os recursos identificados na literatura compuseram as variáveis observadas no modelo, e as capacidades gerencial e comercial constituíram as variáveis latentes.

A AFC permitiu agrupar variáveis que compartilham características de variância e covariância em torno de fatores com perda mínima de informação (Brown, 2015), sendo utilizada para validar os recursos que contribuem para os construtos referentes às capacidades, conforme estabelecidos nas hipóteses da pesquisa.

A Figura 2 apresenta o modelo proposto a partir das construçôes teóricas. As setas indicam a direção das relações esperadas, formuladas segundo as hipóteses. $\mathrm{O}$ modelo sugere que as capacidades gerencial e comercial (elipses) são compostas pelo conjunto de recursos (retângulos).

Como não se observou a normalidade das variáveis pelo teste de Kolmogorov-Smirnov, utilizou-se o estimador de máxima verossimilhança. $\mathrm{O}$ ajuste do modelo foi verificado pelos índices de ajuste e modificação e da matriz de covariância dos resíduos, levando a alteraçóes no modelo teórico original.

O $\chi^{2}$ foi utilizado para avaliar se o modelo estimado reproduz bem a matriz de covariância amostral. Também foram analisadas a raiz quadrada da média do erro de aproximação (RMSEA) robusta, que estimou se os parâmetros do modelo são capazes de reproduzir a covariância populacional, e a raiz padronizada do resíduo médio (SRMR), que verificou diferenças entre as covariâncias preditas e observadas. 


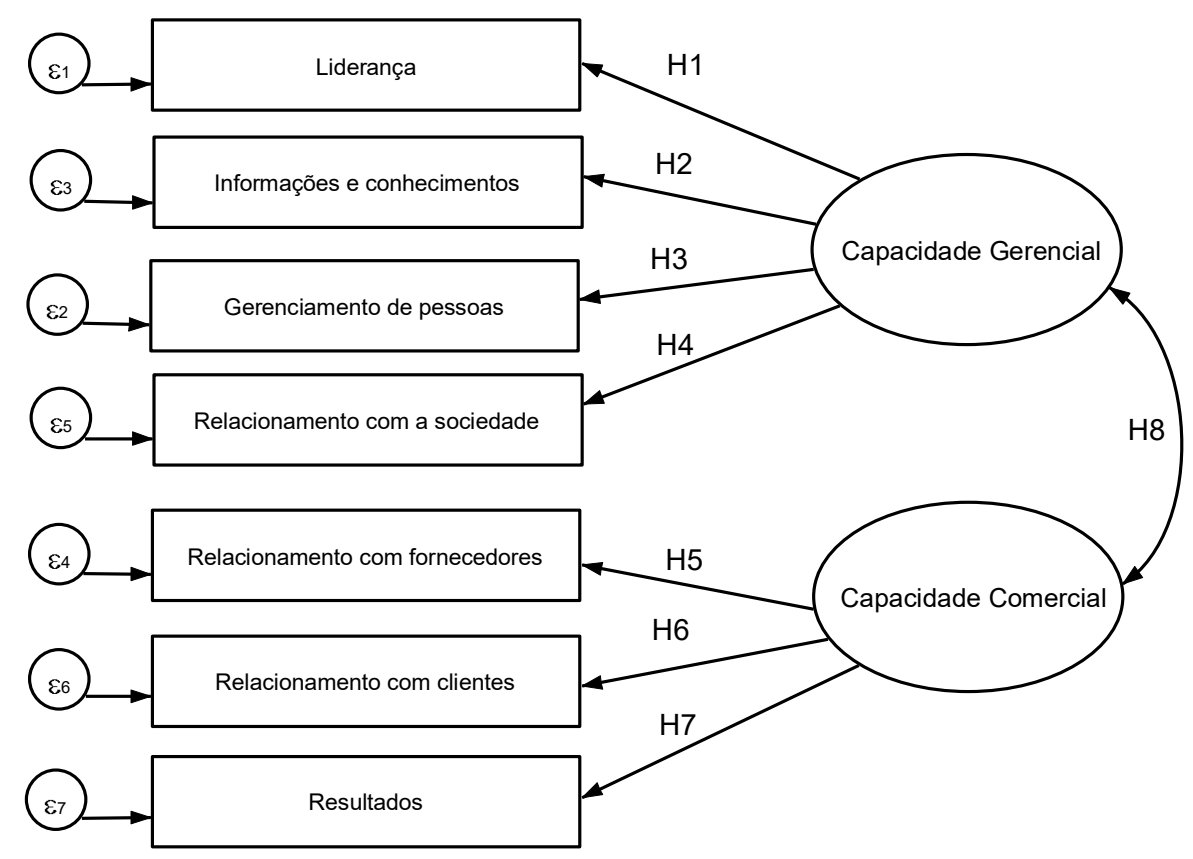

Figura 2. Modelo da análise fatorial confirmatória.

As elipses representam as variáveis latentes, os retângulos representam as variáveis observáveis, e as setas representam a direção da relação. $\varepsilon_{1}$ a $\varepsilon_{7}$ indicam o erro de medida das variáveis observáveis. $\mathrm{H}_{1}$ a $\mathrm{H}_{8}$ indicam as hipóteses do modelo.

Complementarmente, os índices robustos de ajuste comparativo (CFI) e Tucker-Lix (TLI) verificaram o ajuste do modelo comparando-o com um modelo padrão. O modelo foi ajustado pela análise das cargas fatoriais, adotando-se a exclusão de relações não significativas ou com carga inferior a 0,40 , visto que não há evidências empíricas para sua manutenção no modelo, podendo afetar sua confiabilidade (Brown, 2015). As estimativas da AFC e dos índices de ajuste foram realizadas por meio do pacote lavaan do software $\mathrm{R}^{\circledast}$.

A confiabilidade do modelo foi analisada por meio do alfa de Cronbach e do ômega de McDonald. A validade convergente foi mensurada pela variância média extraída $(A V E)$, que representa a variância média entre as variáveis observadas e as latentes. Já a validade discriminante dos construtos foi calculada pelo teste de Heterotrait-Monotrait (HTMT), realizado por meio do pacote semTools do software $\mathrm{R}^{\ominus}$. Por fim, efetuou-se um teste de robustez in-sample, por meio da seleção aleatória de cinco amostras formadas por 300 empresas.

\section{RESULTADOS}

Inicialmente, estão apresentadas informações sobre a composição da amostra do estudo, e as estatísticas descritivas das variáveis observadas. Na segunda etapa, estáo apresentados os resultados da AFC.

$\mathrm{Na}$ Tabela 3, observa-se que a amostra apresenta uma maior concentração no segmento de panificação, com 71 empresas, e menor representação na indústria de móveis, com 53 MPEs. Entretanto, verifica-se um equilíbrio na distribuiçáo quanto aos segmentos. Também se observa maior concentração $(66,55 \%)$ na faixa de 5 a 20 anos, indicando que se trata de empresas mais maduras, que superaram os entraves das fases iniciais. A maioria das empresas conta com poucos funcionários: $66 \%$ da amostra possui até 10 funcionários e apenas $8,05 \%$ apresenta mais de 30 colaboradores, condizente com o perfil das MPEs brasileiras (Serviço Brasileiro de Apoio às Micro e Pequenas Empresas [Sebrae], 2018). 73,60\% estão localizadas na região metropolitana do Recife, enquanto $26,40 \%$ se encontram em outras localidades, como litorais norte e sul, agreste, sertão e zona da mata.

A Tabela 4 apresenta as médias das variáveis analisadas por cada segmento. $\mathrm{O}$ teste de Kruskal-Wallis verificou diferenças no uso dos recursos entre os segmentos, indicando que as empresas apresentam combinaçōes distintas para responder às demandas ambientais, como sugere Penrose (1959). 
Tabela 3. Distribuição da amostra.

\begin{tabular}{|c|c|c|c|}
\hline & Segmento & Número de empresas & Distribuição \\
\hline \multirow{7}{*}{ Segmento } & Gastronomia & 66 & $14,77 \%$ \\
\hline & Indústria de móveis & 53 & $11,86 \%$ \\
\hline & Confecção & 68 & $15,21 \%$ \\
\hline & Vestuário & 63 & $14,09 \%$ \\
\hline & Hotelaria e turismo & 64 & $14,32 \%$ \\
\hline & Material de construção & 62 & $13,87 \%$ \\
\hline & Panificação & 71 & $15,88 \%$ \\
\hline \multirow{5}{*}{$\begin{array}{c}\text { Idade } \\
\text { (em anos) }\end{array}$} & $0-5$ & 55 & $12,30 \%$ \\
\hline & $+5-10$ & 158 & $35,35 \%$ \\
\hline & $+10-20$ & 140 & $31,32 \%$ \\
\hline & $+20-30$ & 60 & $13,42 \%$ \\
\hline & +30 & 34 & $7,61 \%$ \\
\hline \multirow{5}{*}{$\begin{array}{c}\text { Tamanho } \\
\text { (n. }{ }^{\circ} \text { de funcionários) }\end{array}$} & $1-5$ & 177 & $39,60 \%$ \\
\hline & $5-10$ & 118 & $26,40 \%$ \\
\hline & $10-20$ & 87 & $19,46 \%$ \\
\hline & $20-30$ & 29 & $6,49 \%$ \\
\hline & +30 & 36 & $8,05 \%$ \\
\hline \multirow{3}{*}{ Localidade } & Região metropolitana & 329 & $73,60 \%$ \\
\hline & Outras & 118 & $26,40 \%$ \\
\hline & Total de empresas & 447 & \\
\hline
\end{tabular}

Apesar das divergências, as Tabelas 4 e 5 indicam que as MPEs costumam se apoiar no relacionamento com a sociedade e fornecedores; em contrapartida, apresentam menor desempenho na utilizaçáo de resultados. $\mathrm{O}$ alto desvio-padrão e variância sugerem uma heterogeneidade entre as organizaçôes, e o mínimo igual a zero indica a existência de empresas onde esses recursos são insipientes. Conforme demonstrado pelo Sebrae (Sebrae, 2018), as MPEs brasileiras apresentam dificuldades em desenvolver sua gestão, principalmente no que tange aos recursos financeiros, demandando políticas de suporte.

Também foi realizada a análise da correlação entre as variáveis, conforme Tabela 6. As variáveis observadas apresentaram correlação positiva e moderada, o que é esperado, uma vez que o desenvolvimento de um recurso gerencial pode fomentar outro (Jong \& Vermeulen, 2006).

Tabela 4. Recursos por segmento de atuação.

\begin{tabular}{|c|c|c|c|c|c|c|c|}
\hline Variáveis & Liderança & Informaçōes & Pessoas & Sociedade & Fornecedores & Clientes & Resultados \\
\hline Gastronomia & 0,335 & 0,279 & 0,259 & 0,461 & 0,414 & 0,332 & 0,012 \\
\hline Indústria de móveis & 0,454 & 0,379 & 0,397 & 0,457 & 0,548 & 0,590 & 0,256 \\
\hline Confecção & 0,427 & 0,325 & 0,414 & 0,439 & 0,475 & 0,441 & 0,211 \\
\hline Vestuário & 0,519 & 0,457 & 0,396 & 0,629 & 0,518 & 0,499 & 0,137 \\
\hline Hotelaria e turismo & 0,423 & 0,422 & 0,412 & 0,472 & 0,490 & 0,515 & 0,113 \\
\hline $\begin{array}{l}\text { Material de cons- } \\
\text { trução }\end{array}$ & 0,171 & 0,191 & 0,190 & 0,278 & 0,261 & 0,136 & 0,007 \\
\hline Panificação & 0,365 & 0,232 & 0,331 & 0,483 & 0,397 & 0,255 & 0,059 \\
\hline Teste Kruskal-Wallis & $105,38^{* * *}$ & $90,99^{* * *}$ & $82,63^{* * *}$ & $91,63^{* * *}$ & $82,12^{* * *}$ & $185,95^{* * *}$ & $180,80^{* * *}$ \\
\hline
\end{tabular}

Nota. ${ }^{* * *} \mathrm{p}<0,01$. 
Tabela 5. Estatística descritiva.

\begin{tabular}{lccccccc}
\hline Variável observada & Média & Desvio-padráo & Mínimo & Máximo & Variância & Assimetria & Curtose \\
\hline Liderança & 0,383 & 0,218 & 0 & 1 & 0,047 & 0,557 & $-0,088$ \\
Informaçóes & 0,324 & 0,204 & 0 & 1 & 0,042 & 0,545 \\
Pessoas & 0,342 & 0,205 & 0 & 1 & 0,042 & 0,754 & 0,225 \\
Sociedade & 0,461 & 0,214 & 0 & 1 & 0,046 & 0,113 & $-0,192$ \\
Fornecedores & 0,441 & 0,201 & 0 & 1 & 0,041 & 0,171 \\
Clientes & 0,390 & 0,234 & 0 & 1 & 0,055 & 0,452 \\
Resultados & 0,110 & 0,155 & 0 & 1 & 0,024 & $-0,169$ \\
\hline
\end{tabular}

Tabela 6. Análise de correlação das variáveis.

\begin{tabular}{|c|c|c|c|c|c|c|c|}
\hline Variáveis & Liderança & Informações & Pessoas & Sociedade & Fornecedores & Clientes & Resultados \\
\hline Liderança & 1 & & & & & & \\
\hline Informaçōes & 0,7236 & 1 & & & & & \\
\hline Pessoas & 0,7032 & 0,6142 & 1 & & & & \\
\hline Sociedade & 0,5676 & 0,4950 & 0,5156 & 1 & & & \\
\hline Fornecedores & 0,6875 & 0,6575 & 0,6343 & 0,4642 & 1 & & \\
\hline Clientes & 0,6747 & 0,6733 & 0,5667 & 0,4151 & 0,6367 & 1 & \\
\hline Resultados & 0,4560 & 0,4314 & 0,4210 & 0,2636 & 0,4680 & 0,5466 & 1 \\
\hline
\end{tabular}

\section{Resultados da análise fatorial confirmatória}

A AFC foi realizada, primeiramente, conforme o modelo definido na Figura 2. Contudo, a análise das cargas fatoriais, índices de ajuste e modificação sugeriu alteraçóes no modelo original, identificando-se uma relação entre a capacidade gerencial e o relacionamento com fornecedores.

Os índices de ajuste do modelo reespecificado atenderam os valores de referências, conforme a Tabela 7. O $\chi^{2}$ de 26,66 $\operatorname{com} p=0,014$ indicou boa reprodução da matriz de covariância amostral. A RMSEA robusta igual a 0,053 indicou uma reprodução adequada da covariância da população e a SRMR igual a 0,024 demonstrou bom ajuste do modelo.

Os índices robustos CFI $=0,991$ e TLI $=0,985$ também indicaram bom ajuste do modelo. Por fim, foram realizadas as análises de confiabilidade e validade. $\mathrm{O}$ alfa de Cronbach $(\alpha=0,897)$ e ômega de McDonald $(\omega t=0,912)$ demonstraram que o modelo apresenta confiabilidade satisfatória, a $\mathrm{AVE}=0,626$ indicou validade convergente e o $\mathrm{HTMT}=0,87$ indicou a validade divergente do modelo, conforme Gana e Broc (2019). A Tabela 7 apresenta os resultados das métricas do modelo, comparando-os com o valor de referência.

Tabela 7. Resultado das métricas do modelo.

\begin{tabular}{lccc}
\hline \multicolumn{1}{c}{ Métricas } & Resultado & Valor de referência & Referência \\
\hline$\chi^{2}$ & $26,66, p=0,014$ & $p<0,05$ & Brown $(2015)$ \\
RMSEA robusto & 0,053 & $\leq 0,08$ & Brown $(2015)$ \\
SMR & 0,024 & $\leq 0,05$ & Brown $(2015)$ \\
CFI robusto & 0,991 & $>0,95$ & Brown $(2015)$ \\
TLI robusto & 0,985 & $>0,95$ & Brown $(2015)$ \\
Alfa de Cronbach $(\alpha)$ & 0,897 & $>0,70$ & Gana e Broc $(2019)$ \\
Ômega de McDonald $\left(\omega_{\mathrm{t}}\right)$ & 0,912 & $>0,70$ & Gana e Broc (2019) \\
AVE & 0,626 & $>0,5$ & Gana e Broc $(2019)$ \\
HTMT & 0,870 & $<0,90$ & Gana e Broc (2019) \\
\hline
\end{tabular}

Nota. A tabela apresenta as métricas de ajuste, confiabilidade e validade utilizadas para avaliar o modelo. Também são apresentados seus respectivos valores recomendados e referências. 
A Figura 3 apresenta o diagrama do modelo com os resultados da análise fatorial, onde é possível observar a relação entre os recursos analisados e as capacidades, detalhados na Tabela 8.

A Figura 3 e a Tabela 8 apresentam as relaçóes estabelecidas entre os recursos e as capacidades gerencial e comercial. Os resultados indicam que os recursos se mostraram significativos para representar as capacidades orientadas ao negócio.

Os coeficientes obtidos pela AFC sugerem que a Capacidade Gerencial é composta, principalmente, pelo papel da liderança na formulação e na condução das estratégias (coeficiente $=0,883$ ), o compartilhamento de informaçōes e conhecimentos com os stakeholders (coeficiente $=0,823)$, o relacionamento com a sociedade (coeficiente $=0,611)$ e o gerenciamento das pessoas (coeficiente $=0,780$ ), confirmando as hipóteses levantadas na pesquisa. Porém, os resultados revelam ainda que o relacionamento com fornecedores também contribui para a capacidade da empresa em gerenciar seus ativos, apresentando relação positiva e moderada com a capacidade gerencial (coeficiente $=0,797$ )

Zawislak et al. (2018) sugerem que a capacidade gerencial é composta por três elementos centrais: planejamento estratégico, recursos humanos e normas e procedimentos. Os resultados aqui obtidos corroboram os dos autores, porém também indicam a relevância de outros recursos no contexto das MPEs.

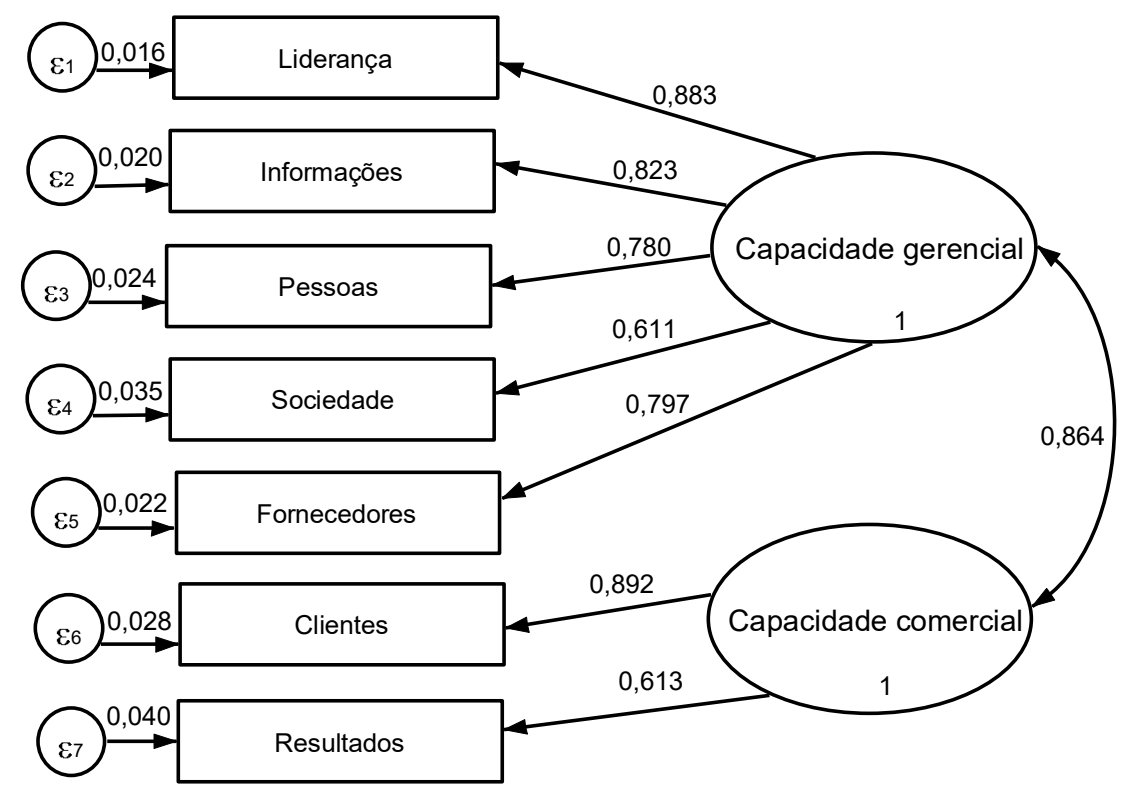

Figura 3. Coeficientes padronizados do modelo.

As elipses representam as variáveis latentes e os retângulos representam as variáveis observáveis, avaliadas por meio dos aspectos apresentados na Tabela 2.

Tabela 8. Resultado dos testes de hipótese.

\begin{tabular}{|c|c|c|c|c|}
\hline Hipótese & Relação & Coeficiente & Erro-padrão & Resultado \\
\hline $\mathrm{H}_{1}$ & Liderança $\leftarrow$ Capacidade Gerencial & $0,883^{* * *}$ & 0,016 & Confirmada \\
\hline $\mathrm{H}_{2}$ & Informaçōes $\leftarrow$ Capacidade Gerencial & $0,823^{* * *}$ & 0,020 & Confirmada \\
\hline $\mathrm{H}_{3}$ & Pessoas $\leftarrow$ Capacidade Gerencial & $0,780^{* * *}$ & 0,024 & Confirmada \\
\hline $\mathrm{H}_{4}$ & Sociedade $\leftarrow$ Capacidade Gerencial & $0,611^{* * *}$ & 0,035 & Confirmada \\
\hline- & Fornecedores $\leftarrow$ Capacidade Gerencial & $0,797^{* * *}$ & 0,022 & - \\
\hline $\mathrm{H}_{6}$ & Clientes $\leftarrow$ Capacidade Comercial & $0,892^{* * *}$ & 0,028 & Confirmada \\
\hline $\mathrm{H}_{7}$ & Resultados $\leftarrow$ Capacidade Comercial & $0,613^{* * *}$ & 0,040 & Confirmada \\
\hline $\mathrm{H}_{8}$ & Capacidade Comercial $\leftarrow$ Capacidade Gerencial & $0,864^{* * *}$ & 0,033 & Confirmada \\
\hline
\end{tabular}

Nota. As métricas do modelo e os respectivos valores de referência encontram-se detalhados na Tabela 7. ${ }^{* * *} p<0,01$. 
De maneira geral, os resultados vão ao encontro da literatura. Diversos autores discutem o papel do empreendedor como figura central no desenvolvimento da inovação (Bayarçelik et al., 2014; Kim et al., 2018; Le \& Lei, 2019; Martínez-Román \& Romero, 2017; Vasconcelos \& Oliveira, 2018). Este estudo verifica uma relação positiva entre a liderança e a capacidade gerencial, permitindo aceitar a $\mathrm{H}_{1}$. O resultado destaca a relevância da figura do líder para a capacidade de as MPEs coordenarem suas atividades, facilitando o surgimento de inovaçóes. Verifica-se que sua habilidade em definir as estratégias, aplicar e compartilhar conhecimentos e incentivar a participaçáo dos funcionários auxilia na coordenação no desenvolvimento de novas ideias.

A pesquisa demonstra que a capacidade gerencial também é composta pelo compartilhamento de informaçóes e conhecimentos; o relacionamento significativo entre as variáveis permite aceitar a $\mathrm{H}_{2}$. Kim et al. (2018), Le e Lei (2019), Martínez-Román e Romero (2017) e Vasconcelos e Oliveira (2018) já haviam demonstrado que as redes de conhecimento colaboram para a promoção de inovaçóes, possibilitando o acesso a novos conhecimentos. Os resultados obtidos corroboram os anteriores, indicando que a relação entre as redes de conhecimento e a inovação pode ser explicada por sua contribuição à capacidade gerencial.

Os resultados sugerem que as redes de conhecimento possibilitam que as MPEs obtenham informaçóes que promovem novas habilidades e atividades. As informaçôes comparativas dos concorrentes podem facilitar a identificação de oportunidades de melhorias. Já o registro de lições aprendidas e o compartilhamento de informaçóes com a equipe podem auxiliar na execuçáo de atividades e novas rotinas. Verifica-se, portanto, que o compartilhamento de informaçóes facilita o gerenciamento de conhecimentos e habilidades, possibilitando o alcance de objetivos com maior eficiência.

Do mesmo modo, a AFC também demonstra que a gestáo das pessoas contribui para a capacidade gerencial da MPE, sendo aceita $\mathrm{a} \mathrm{H}_{3}$. Como sugere Penrose (1959), a firma é uma coleção de recursos produtivos, e os recursos humanos, assim como os físicos, são importantes para o crescimento organizacional. E os resultados do estudo indicam que a definição de funçōes e tarefas, a capacitação do funcionário e os programas de bem-estar permitem que o funcionário desenvolva habilidades e autonomia para promover novas ideias e modificar suas atividades e tarefas, traduzindo-se em inovaçóes.

Da mesma forma, verifica-se que a capacidade gerencial também é composta pelo relacionamento com a sociedade, sendo aceita $\mathrm{a} \mathrm{H}_{4}$. O resultado sugere que o atendimento aos aspectos regulatórios e sociais facilita a coordenação das atividades que contribuem para a inovação. As exigências sociais, ambientais e regulatórias demandam uma coordenação de esforços que impulsionam as MPEs a repensar suas atividades e processos, como sugerem Vasconcelos e Oliveira (2018).

Diferentemente do esperado, o relacionamento com fornecedores não manteve relação com a capacidade comercial, sendo rejeitada a $\mathrm{H}_{5}$. Zawislak et al. (2018) destacam a seleção criteriosa dos fornecedores e a imposição de condiçóes de negociação como elemento importante para a capacidade comercial. Contudo, a ausência desta relação pode ser resultado do baixo poder de negociaçáo que as MPEs têm sobre seus fornecedores, dificultando a obtenção de vantagens comerciais.

Por outro lado, verifica-se relação significativa com a capacidade gerencial, enfatizando a relevância das parcerias estabelecidas com fornecedores para melhoria dos processos produtivos, como sugerido por Iddris (2019) e Kamasak (2015). Ademais, os processos de seleção e avaliação dos fornecedores e o mapeamento e controle dos processos podem contribuir para a reformulação das atividades e rotinas, facilitando o desenvolvimento de práticas inovadoras.

Por sua vez, a capacidade comercial, ou seja, a capacidade de minimizar os custos de transação, é composta pelo relacionamento mantido com os clientes (coeficiente $=0,892$ ) e os resultados obtidos pela organização (coeficiente $=0,613)$. A importância do relacionamento com o cliente para a promoção da inovação é discutida por diversos autores (Bayarçelik et al., 2014; Genis-Gruber \& Ögüt, 2014; Iddris, 2019; Kamasak, 2015; Silva et al., 2012; Vasconcelos \& Oliveira, 2018), que apontam que esta proximidade auxilia as empresas a compreender suas necessidades e a desenvolver novos produtos e serviços.

Neste estudo, verifica-se que o relacionamento contribui mais especificamente com a capacidade comercial das MPEs, uma vez que se verifica uma relação positiva e significativa entre o recurso e a capacidade, sendo aceita a $\mathrm{H}_{6}$. Enquanto o desconhecimento sobre os hábitos de consumo dos clientes é apontado como fator relevante para a mortalidade das empresas (Sebrae, 2018), os esforços em analisar suas expectativas e avaliar suas reclamaçóes e satisfaçóes auxiliam o desenvolvimento de inovaçôes, como propóem Bayarçelik et al. (2014), Kamasak (2015), Iddris (2019) e Vasconcelos e Oliveira (2018). Além disso, também facilitam a fidelização e retenção dos clientes, possibilitando reduzir custos de transação, conforme Zawislak et al. (2018).

A AFC ainda indica que os resultados obtidos pelas MPEs também contribuem para a capacidade comercial, permitindo aceitar a $\mathrm{H}_{7}$. Ainda que tenham limitaçóes na disponibilidade de recursos financeiros, como apresentado na Tabela 4, verifica-se que seus resultados são relevantes para que consigam comercializar seus produtos. Tal proposição vai ao encontro de Bayarçelik et al. (2014) 
e Vasconcelos et al. (2020), que indicam a relevância dos resultados financeiros e não financeiros para as inovaçóes.

Verifica-se ainda relação positiva e significativa entre a capacidade gerencial e a comercial, confirmando a $\mathrm{H}_{8}$. Como propóem Zawislak et al. (2012), as capacidades orientadas ao negócio estáo relacionadas e contribuem de maneira conjunta para a inovação. Apesar da correlação moderada, o teste de HTMT apontou a validade divergente dos construtos, reforçando sua distinção.

Por fim, buscou-se analisar a robustez do modelo por meio de sua replicação em novas amostras, o que pode ser realizado pela abordagem out-of-the sample ou in-sample. No teste out-of-the sample, os resultados são comparados com dados externos, sendo considerado, por isso, mais confiável (Inoue \& Kilian, 2005). Contudo, enfrenta limitaçóes, visto que pode exigir uma ampla amostra para lidar com as dimensionalidades das relações.

Neste estudo, por exemplo, as limitaçóes no acesso à base de dados inviabilizaram a obtenção de uma amostra adicional com tamanho suficiente para realizar a validação do modelo. Desta forma, utilizou-se a abordagem in-sample, replicando o modelo em cinco amostras aleatórias com 300 empresas, retiradas da amostra inicial.

Para Inoue e Kilian (2005), a utilização da abordagem in-sample não reduz a confiabilidade dos resultados $\mathrm{e}$ permite que se obtenham insights teóricos sobre o modelo. Ademais, deve-se destacar que também foram realizados testes complementares, como de alfa de Cronbach, ômega de McDonald, AVE e HTMT, atestando a confiabilidade e as validades convergentes e divergentes do modelo e das subamostras.

Procedendo-se a análise, verifica-se que os coeficientes das relaçóes se mantiveram significativos, obedecendo ao intervalo de confiança do modelo original. É possível observar que o teste de $\chi 2$ das amostras 4 e 5 não foi significativo, contudo, seu resultado é sensível ao tamanho da amostra e à não normalidade dos dados (Tanaka, 1993), sugerindo uma análise complementar pelos índices de ajuste e confiabilidade, cujos resultados atendem as especificaçóes, indicando a robustez e a confiabilidade do modelo.

Tabela 9. Comparação dos resultados das amostras.

\begin{tabular}{|c|c|c|c|c|c|}
\hline Relação & Amostra 1 & Amostra 2 & Amostra 3 & Amostra 4 & Amostra 5 \\
\hline Liderança $\leftarrow$ Capacidade Gerencial & $0,881^{* * *}$ & $0,897^{* * *}$ & $0,872^{* * *}$ & $0,886^{* * *}$ & $0,867^{* * *}$ \\
\hline Informaçóes $\leftarrow$ Capacidade Gerencial & $0,826^{* * *}$ & $0,843^{* * *}$ & $0,828^{* * *}$ & $0,829^{* * *}$ & $0,836^{* * *}$ \\
\hline Pessoas $\leftarrow$ Capacidade Gerencial & $0,762^{* * *}$ & $0,783^{* * *}$ & $0,783^{* * *}$ & $0,811^{* * *}$ & $0,790^{* * *}$ \\
\hline Sociedade $\leftarrow$ Capacidade Gerencial & $0,607^{* * *}$ & $0,609^{* * *}$ & $0,623^{* * *}$ & $0,662^{* * *}$ & $0,603^{* * *}$ \\
\hline Fornecedores $\leftarrow$ Capacidade Gerencial & $0,770^{* * *}$ & $0,806^{* * *}$ & $0,825^{* * *}$ & $0,810^{* * *}$ & $0,784^{* * *}$ \\
\hline Clientes $\leftarrow$ Capacidade Comercial & $0,899^{* * *}$ & $0,900^{* * *}$ & $0,884^{* * *}$ & $0,911^{* * *}$ & $0,904^{* * *}$ \\
\hline Resultados $\leftarrow$ Capacidade Comercial & $0,631^{* * *}$ & $0,643^{* * *}$ & $0,617^{* * *}$ & $0,624^{* * *}$ & $0,638^{* * *}$ \\
\hline Capacidade Comercial $\leftarrow$ Capacidade Gerencial & $0,829^{* * *}$ & $0,866^{* * *}$ & $0,873^{* * *}$ & $0,873^{* * *}$ & $0,871^{* * *}$ \\
\hline$\chi^{2}$ & $31,467^{* * *}$ & $31,832^{* * *}$ & $32,680^{* * *}$ & 13,337 & 17,219 \\
\hline CFI robusto & 0,981 & 0,983 & 0,981 & 0,996 & 0,996 \\
\hline TLI robusto & 0,969 & 0,972 & 0,970 & 0,993 & 0,993 \\
\hline RMSEA robusta & 0,074 & 0,075 & 0,076 & 0,037 & 0,036 \\
\hline SMR & 0,033 & 0,026 & 0,031 & 0,024 & 0,021 \\
\hline Alfa de Cronbach & 0,891 & 0,904 & 0,901 & 0,909 & 0,899 \\
\hline Ômega de McDonald & 0,913 & 0,923 & 0,920 & 0,928 & 0,916 \\
\hline AVE & 0,622 & 0,646 & 0,630 & 0,661 & 0,630 \\
\hline HTMT & 0,834 & 0,870 & 0,871 & 0,871 & 0,884 \\
\hline
\end{tabular}

Nota. Cada amostra contempla 300 empresas selecionadas aleatoriamente da amostra inicial utilizada neste estudo. As subamostras foram utilizadas para analisar a robustez do modelo. Os resultados das métricas dos modelos podem ser avaliados por meio dos valores de referência apresentados na Tabela $7 .{ }^{* * *} p<0,01$.

Por fim, efetuou-se a estimativa das variáveis latentes, cuja dispersão está apresentada na Figura 4. É possível observar uma relação linear entre as capacidades de inovação orientadas ao negócio, corroborando os resultados da AFC.
A Figura 4 demonstra uma concentração de MPEs no centro para o quadrante inferior e esquerdo, de baixa capacidade comercial e gerencial, revelando dificuldades enfrentadas no desenvolvimento dos recursos. A figura 
também apresenta diferenças nas distribuições entre os segmentos analisados. As MPEs de material de construção e panificação, por exemplo, apresentam-se concentradas no quadrante de baixa capacidade comercial e gerencial, sugerindo que podem enfrentar maiores barreiras no desenvolvimento da inovação. A indústria de móveis e vestuário apresenta maior concentração no quadrante de alta capacidade comercial e gerencial, indicando que o segmento tem maior facilidade em desenvolver os recursos e as habilidades necessárias para inovar.
Tais resultados são reforçados pelo teste de KruskalWallis, que indica as diferenças das capacidades entre os segmentos de atuação. Como observado na Tabela 10, material de construçâo apresenta menor desempenho médio dentre os segmentos para ambas as capacidades, enquanto as indústrias de móveis e vestuários apresentaram os melhores resultados. Apesar de os segmentos de gastronomia e panificação também registrarem baixa capacidade, a Figura 4 demonstra que há uma maior dispersão das empresas, indicando que algumas MPEs conseguem superar os entraves e desenvolver seus recursos gerenciais.
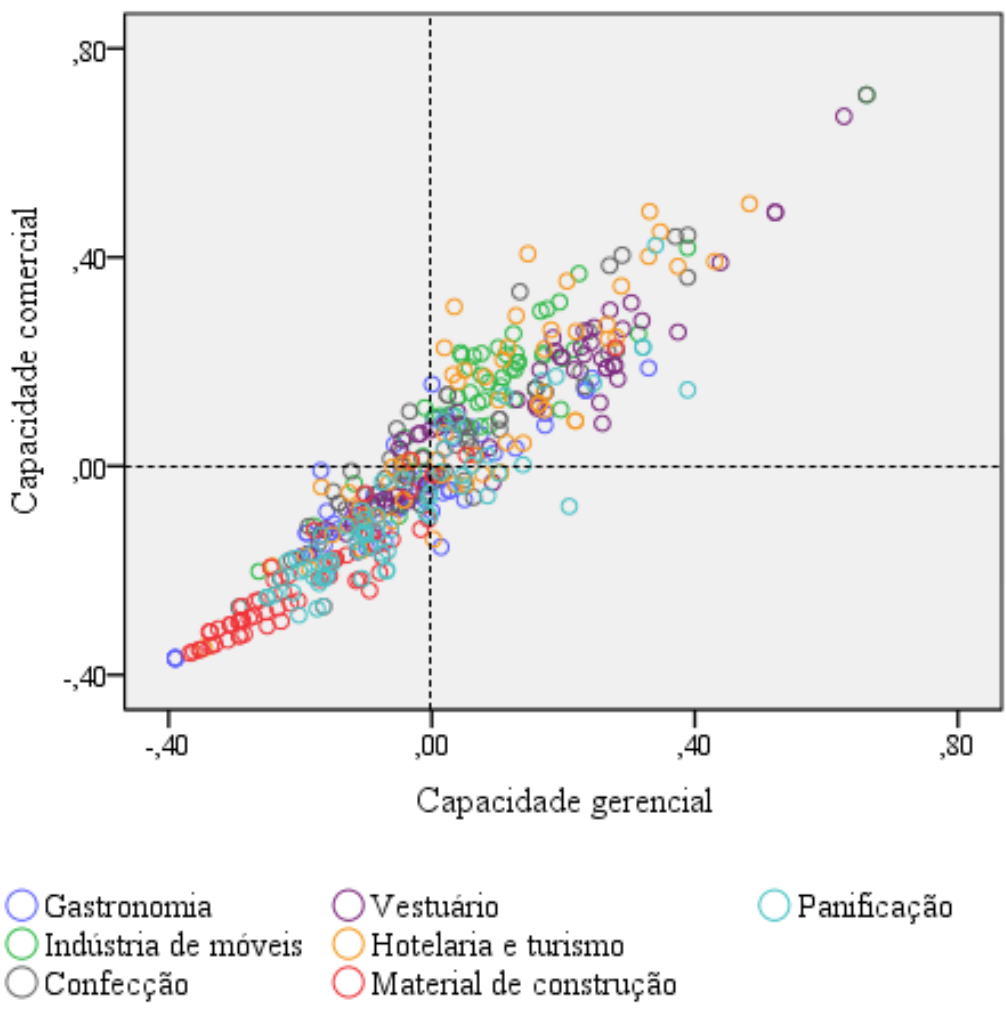

Panificação

Confecção

Material de construção

Figura 4. Dispersão das empresas pelas capacidades de inovação.

$\mathrm{O}$ gráfico apresenta a dispersão das empresas por meio das estimativas das variáveis latentes, $\mathrm{o}$ eixo $\mathrm{x}$ indica a capacidade gerencial e o eixo y indica a capacidade comercial, identificadas pelo segmento de atuação. Os segmentos de material de construção e panificação apresentam uma concentração de empresas com baixa capacidade comercial e gerencial, enquanto a indústria de móveis apresenta maior concentração de empresas com capacidades mais elevadas.

Tabela 10. Capacidade comercial e gerencial por segmento de atuação.

\begin{tabular}{lcc}
\hline Segmento & Capacidade comercial & Capacidade gerencial \\
\hline Gastronomia & $-0,064$ & $-0,051$ \\
Indústria de móveis & 0,154 & 0,088 \\
Confecção & 0,057 & 0,039 \\
Vestuário & 0,105 & 0,114 \\
Hotelaria e turismo & 0,087 & 0,066 \\
Material de construção & $-0,217$ & $-0,191$ \\
Panificaçáo & $-0,092$ & $-0,049$ \\
Teste de Kruskal-Wallis & $187,91^{* * *}$ & $134,41^{* * *}$ \\
\hline
\end{tabular}

Nota. ${ }^{* * *} p<0,01$. 
De maneira geral, os resultados indicam a existência de uma heterogeneidade nas capacidades de inovaçáo referentes às MPEs, diferentemente de Zawislak et al. (2018), o que pode ser causado pelas barreiras e dificuldades que cada segmento enfrenta. Diante desses contrapontos, as MPEs procuram estruturar diferentes arranjos para desenvolver suas habilidades e promover inovaçóes, o que requer esforços e suportes específicos voltados a suas necessidades.

\section{CONCLUSÕES}

Teece et al. (1997) propóem que a formulação de estratégias em excesso pode levar ao desinvestimento nas capacidades dinâmicas. Contudo, o presente artigo sugere que a formulação de estratégias eficientes de inovação pode ocorrer por meio dos investimentos nas capacidades dinâmicas e nos recursos gerenciais. Todavia, ainda se constitui como desafio identificar e mensurar as capacidades dinâmicas e, deste modo, a pesquisa constitui-se como um esforço em demonstrar como a capacidade de inovação pode ser operacionalizada nas MPEs, dadas as limitaçóes que enfrentam no acesso e uso das tecnologias.

Ainda que a tecnologia seja relevante para inovar (Dosi et al., 1988), os resultados demonstram que as habilidades gerenciais não são apenas recursos suplementares, como indicam Guan e Ma (2003), mas se tornam ativos centrais para a inovaçáo em empresas pouco intensivas em tecnologias. Além de demonstrar a relevância das capacidades comercial e gerencial, o estudo também demonstra como estas capacidades são constituídas e operacionalizadas, o que pode apresentar uma contribuição relevante para a literatura, visto que náo há consenso sobre o tema (Iddris, 2019).

Estudos anteriores já analisaram os recursos como determinantes da capacidade de inovação, porém partem de uma relaçáo direta e individualizada. Kim et al. (2018), Le e Lei (2019) e Martínez-Román e Romero (2017), por exemplo, destacam a relevância de liderança e da rede de conhecimentos no desenvolvimento de inovações; Iddris (2019) e Kamasak (2015) salientam o relacionamento com fornecedores e clientes; já Vasconcelos et al. (2020) enfatizam a contribuição de aspectos financeiros.

Este estudo, contudo, parte de uma perspectiva mais ampla e contempla as interaçóes entre os recursos gerenciais tratados naliteratura. Os resultados aqui encontrados corroboram os estudos anteriores ao demonstrar a pertinência desses recursos para a inovação nas MPEs. Porém, traçam uma relação indireta entre os recursos e a inovação, demonstrando que sua relevância se dá pela contribuição às capacidades gerenciais e comerciais.

Assim, verifica-se que a capacidade gerencial é composta pelo relacionamento com a sociedade e fornecedores, a liderança, o compartilhamento de informaçóes e conhecimentos, e o gerenciamento de pessoas. E a capacidade comercial é composta pelo relacionamento com os clientes e os resultados obtidos pela firma.

Ao partir da perspectiva da teoria dos recursos, o framework amplia o modelo proposto por Zawislak et al. (2018), evidenciando novos recursos (liderança, informações e conhecimentos e resultados) e configuraçóes para as capacidades de inovaçáo. Diferentemente dos autores, observa-se que o relacionamento com fornecedores não mantém relação com a capacidade comercial, o que pode ser resultado do baixo poder de barganha dos pequenos negócios, dificultando a negociação de preços, prazos e condiçóes de entrega. Porém, verifica-se forte relaçáo com a capacidade gerencial, sugerindo que ainda que não se obtenha vantagens comerciais, promovem-se melhorias das atividades e processos internos, conforme sugerido por Kamasak (2015).

As diferenças nas configuraçóes dos recursos e capacidades reforçam a necessidade de uma análise particular das MPEs. Diferentemente de Zawislak et al. (2018), verifica-se que as capacidades não são homogêneas, e que as firmas procuram desenvolver e combinar os recursos de acordo com as demandas e restriçóes ambientais, como proposto por Penrose (1959). A fim de superar barreiras, podem ser desenvolvidos programas e políticas que forneçam instruçóes, assessorias e consultorias para que as MPEs consigam superar os gargalos nos usos dos recursos.

Ainda que o artigo represente uma pequena contribuição ao estudo das capacidades dinâmicas e apresente uma perspectiva limitada do modelo de Zawislak et al. (2012), concentrando-se nas capacidades guiadas ao negócio, ele se constitui em um esforço em identificar os recursos atrelados às capacidades inovadoras nas MPEs, permitindo que tais organizaçōes se empenhem para desenvolvê-los a fim de obter lucros extraordinários advindos da inovação (Schumpeter, 1988). Não se busca, contudo, limitar ou esgotar a contribuição dos recursos, e sim demonstrar a relevância para o desenvolvimento da inovaçáo.

Por fim, destaca-se que o modelo apresentado demonstra boa especificaçáo e robustez, conforme evidenciado pelos índices de confiabilidade e validade e pela replicação do modelo em amostras in-sample. Contudo, destaca-se que a limitação no acesso aos dados inviabilizou a replicação do modelo em amostras out-of-sample. Ademais, os dados revelam a percepçáo do gestor sobre a empresa, e náo necessariamente a realidade organizacional e, como sugerem Tometich, Fracasso, Zen e Engelman (2019), as capacidades de inovaçáo são reconfiguradas pelas decisões organizacionais. Por isso, sugere-se o desenvolvimento de novos estudos que utilizem dados longitudinais e que analisem as capacidades guiadas pela tecnologia. Também se sugere a aplicação em outros segmentos, que utilizem níveis diferentes de tecnologias, o que pode revelar novas configuraçóes. 


\section{REFERÊNCIAS}

Alves, A., Barbieux, D., Reichert, F., Tello-Gamarra, J. \& Zawislak, P. (2017). Innovation and dynamic capabilities of the firm: Defining an assessment model. Revista de Administração de Empresas, 57(3), 232-244. https://doi.org/10.1590/s0034-759020170304

Bayarçelik, E., Taşel, F., \& Apak, S. (2014). A research on determining innovation factors for SMEs. Procedia - Social and Behavioral Sciences, 150, 202-211. https://doi.org/10.1016/j.sbspro.2014.09.032

Brown, T. (2015). Confirmatory factor analysis for applied research. New York, NY: The Guilford Press.

Bos-Brouwers, H. (2009). Corporate sustainability and innovation in SMEs: Evidence of themes and activities in practice. Business Strategy and the Environment, 19(7), 417-435. https://doi.org/10.1002/bse.652

Coase, R. H. (1937). The nature of the firm. Economica, 4(16), 386-405. Retrieved from https://www.jstor.org/stable/2626876?seq=1

Dosi, G., Freeman, C., \& Nelson, R. (1988). Technical change and economic theory (Vol. 988). London: Printer.

Eisenhardt, K. M., \& Martin, J. A. (2000). Dynamic capabilities: what are they? Strategic Management Journal, 21(10-11), 1105-1121. https://doi. org/10.1002/1097-0266(200010/11)21:10/11<1105::AID$\underline{\mathrm{SMI} 133>3.0 . \mathrm{CO} ; 2-\mathrm{E}}$

El Elj, M., \& Abassi, B. (2014). The determinants of innovation: an empirical analysis in Egypt, Jordan, Syria and Turkey. Canadian Journal of Development Studies, 35(4), 560-578. https://doi.org/10.1080/02255189.2014.934787

Farace, S., \& Mazzotta, F. (2015). The effect of human capital and networks on knowledge and innovation in SMEs. Journal of Innovation Economics, 16(1), 39-71. https://doi.org/10.3917/jie.016.0039

Gana, K., Broc, G. (2019). Structural equation modeling with lavaan. London: John Wiley \& Sons.

Genis-Gruber, A., \& Öğ̈̈t, H. (2014). Environmental factors affecting innovation strategies of companies: Customers and suppliers effect. Procedia - Social and Behavioral Sciences, 150(11), 718-725. https://doi.org/10.1016/j.sbspro.2014.09.033

Guan, J., \& Ma, N. (2003). Innovative capability and export performance of Chinese firms. Technovation, 23(9), 737747. https://doi.org/10.1016/S0166-4972(02)00013-5

Iddris, F. (2019). Innovation capability and product innovation performance: The case of low-tech manufacturing firms. European Business Review, 31(5), 646-668. https://doi.org/10.1016/S0166-4972(02)00013-5

Inoue, A., \& Kilian, L. (2005). In-sample or out-ofsample tests of predictability: Which one should we use? Econometric Reviews, 23(4), 371-402. https://doi.org/10.1081/ETC-200040785
Jong, J., \& Vermeulen, P. (2006). Determinants of product innovation in small firms: A comparison across industries. International Small Business Journal, 24(6), 587-609. https://doi.org/10.1177/0266242606069268

Kamasak, R. (2015). Determinants of innovation performance: A resource-based study. Procedia Social and Behavioral Sciences, 195, 1330-1337. https://doi.org/10.1016/j.sbspro.2015.06.311

Karpak, B., \& Topcu, I. (2010). Small medium manufacturing enterprises in Turkey: An analytic network process framework for prioritizing factors affecting success. International Journal of Production Economics, 125(1), 6070. https://doi.org/10.1016/j.ijpe.2010.01.001

Kim, M., Park, J., \& Paik, J. (2018). Factors influencing innovation capability of small and medium-sized enterprises in Korean manufacturing sector: Facilitators, barriers and moderators. International Journal of Technology Management, 76(3-4), 214-235. https://doi.org/10.1504/IJTM.2018.10012461

Laforet, S., \& Tann, J. (2006). Innovative characteristics of small manufacturing firms. Journal of Small Business and Enterprise Development, 13(3), 363-380. https://doi.org/10.1108/14626000610680253

Laforet, S. (2011). A framework of organizational innovation and outcomes in SMEs. International Journal of Entrepreneurial Behavior \& Research, 17(4), 380-408. https://doi.org/10.1108/13552551111139638

Lawson, B., \& Samson, D. (2001). Developing innovation capability in organizations: A dynamic capabilities approach. International Journal of Innovation Management, 5(3), 377-400. https://doi.org/10.1142/S1363919601000427

Le, P., \& Lei, H. (2019). Determinants of innovation capability: The roles of transformational leadership, knowledge sharing and perceived organizational support. Journal of Knowledge Management, 23(3), 527-547. https://doi.org/10.1108/JKM-09-2018-0568

Lee, F., \& Newton, K. (2000). Innovation of SMEs in the knowledge-based economy. Journal of Small Business \& Entrepreneurship, 15(4), 2-31. https://doi.org/10.1080/08276331.2000.10593291

Lei Complementar n. 155, de 27 de outubro de 2016. (2016). Altera a Lei Complementar $\mathrm{n}^{\mathrm{o}}$ 123, de 14 de dezembro de 2006. Retrieved from http://www.planalto.gov.br/ccivil 03/leis/lcp/lcp155.htm

Martínez-Román, J., \& Romero, I. (2017). Determinants of innovativeness in SMEs: Disentangling core innovation and technology adoption capabilities. Review of Managerial Science, 11(3), 543-569. https://doi.org/10.1007/s11846-016-0196-x

Nelson, R. R., \& Winter, S. G. (1982). An evolutionary theory of economic change. Cambridge: Belknap Press. 
Nidumolu, R., Prahalad, C., \& Rangaswami, M. (2009). Why sustainability is now the key driver of innovation. Harvard Business Review, Reprint R0909E. Retrieved from https:// www.academia.edu/8421329/Why Sustainability Is Now the Key Driver of Innovation The Idea in Brief the core idea 1 Article Summary 3 Why Sustainability Is Now the Key Driver of Innovation

Pavitt, K. (1984). Setorial patters of technical change: Towards a taxonomy and a theory. Research Policy, 13(6), p. 343-373. https://doi.org/10.1016/0048-7333(84)90018-0

Penrose, E. (1959). The theory of growth of firm. New York, NY: Oxford University Press.

Popadiuk, S., Luz, A., \& Kretschmer, C. (2018). Dynamic capabilities and ambidexterity: how are these concepts related? RAC. Revista de Administração Contemporânea, 22(5), 639-660. https://doi.org/10.1590/1982-7849rac2018180135

Raghuvanshi, J., Ghosh, P., \& Agrawal, R. (2019). Taxonomy of innovation capability framework with future directions. International Journal of Business Excellence, 17(3), p. $265-$ 289. https://doi.org/10.1504/IJBEX.2019.10019304

Rogers, M. (2004). Networks, firm size and innovation. Small Business Economics, 22(2), 141-153. https://doi.org/10.1023/B:SBEJ.0000014451.99047.69

Saunila, M. (2019). Innovation capability in SMEs: A systematic review of the literature. Journal of Innovation \& Knowledge. https://doi.org/10.1016/j.jik.2019.11.002

Schumpeter, J. A. (1984). Capitalismo, socialismo e democracia. Rio de Janeiro: Zahar.

Schumpeter, J. A. (1988). A teoria do desenvolvimento econômico. São Paulo, SP: Nova Cultural.

Serviço Brasileiro de Apoio às Micro e Pequenas Empresas. (2018). Perfil das microempresas e empresas de pequeno porte 2018. https://www.sebrae.com.br/sites/PortalSebrae/ufs/ro/artigos/ perfil-das-microempresas-e-empresas-de-pequeno-porte2018,a2fb479851b33610VgnVCM1000004c00210aRCR D? origem $=$ tema\&codTema $=2$

Serviço Brasileiro de Apoio às Micro e Pequenas Empresas. (2020). Data SEBRAE. Retrieved from https://datasebrae.com.br/

Silva, M., Mainardes, E., Raposo, M., \& Sousa, G. (2012). Determinantes internos e externos da capacidade inovadora das empresas de serviços portuguesas: Modelo logit. Revista de Gestão, 19(1), 39-54. https://doi.org/10.5700/rege450
Söllner, R. (2010). Human capital diversity and product innovation: a micro-level analysis. Jena Economic Research Papers, 27, 1-33. Retrieved from https://www.econstor.eu/ bitstream/10419/32631/1/625854918.pdf

Tanaka, J. (1993). Multifaced conceptions of fit in strucutural equation models. In K. A. Bollen, \& J. S. Long (Eds.), Testing structural equation models (pp. 10-39). Newbury Park: Sage Publications.

Teece, D. J. (2007). Explicating dynamic capabilities: The nature and microfoundations of (sustainable) enterprise performance. Strategic Management Journal, 28(13), 1319-1350. https://doi.org/10.1002/smj.640

Teece, D. J., Pisano G., \& Shuen A. (1997). Dynamic capabilities and strategic management. Strategic Management Journal, 18(7), 509-533. https://doi.org/10.1002/(SICI)10970266(199708)18:7<509::AID-SMJ882>3.0.CO;2-Z

Tometich, P., Fracasso, E., Zen, A., \& Engelman, R. (2019). A decisão de inovar e o movimento das capacidades dinâmicas. Gestâo \& Produção, 26(2), e3627. http://dx.doi.org/10.1590/0104-530x-3627-19

Vasconcelos, R. B. B., \& Oliveira, M. R. G. (2018). Determinantes da inovação em micro e pequenas empresas: Uma abordagem gerencial. Revista de Administração de Empresas, 58(4), 249364. http://dx.doi.org/10.1590/s0034-759020180402

Vasconcelos, R. B. B, Vieira, R. S., \& Silveira, D. S. (2020). What's the recipe to innovate? An analysis of the determinants of the degree of innovation in the gastronomy segment. International Journal of Innovation Management, 24(1), 2050005. https://doi.org/10.1142/S136391962050005X

Williamson, O. (1985). The economic institutions of capitalism. New York, NY: Free Press.

Zawislak, P., Alves, C., Tello-Gamarra, J., Barbieux, D., \& Reichert, F. (2012). Innovation capability: from technology development to transaction capability. Journal of Technology Management \& Innovation, 7(2), 14-27. https://doi.org/10.4067/S0718-27242012000200002

Zawislak, P., Fracasso, E., \& Tello-Gamarra, J. (2018). Technological intensity and innovation capability in industrial firms. Innovation \& Management Review, 15(2), 189-207. https://doi.org/10.1108/INMR-04-2018-012 


\section{Autoria}

\section{Renata Braga Berenguer de Vasconcelos*}

Universidade Federal de Pernambuco, Centro de Ciências Sociais Aplicadas

Av. Prof. Moraes Rego, no 1235, Cidade Universitária, 50670-901, Recife, PE, Brasil.

E-mail: renata_berenguer@hotmail.com

(1) https://orcid.org/0000-0003-4184-5694

\section{Joséte Florencio dos Santos}

Universidade Federal de Pernambuco, Centro de Ciências Sociais Aplicadas

Av. Prof. Moraes Rego, no 1235, Cidade Universitária, 50670-901, Recife, PE, Brasil.

E-mail: jfs@ufpe.br

(10) https://orcid.org/0000-0002-5366-2548

\section{Jackeline Amantino de Andrade}

Universidade Federal de Pernambuco, Centro de Ciências Sociais Aplicadas

Av. Prof. Moraes Rego, no 1235, Cidade Universitária, 50670-901, Recife, PE, Brasil.

E-mail: jackeline.amantino@gmail.com

(1) https://orcid.org/0000-0002-6451-4049

* Autora Correspondente

\section{Financiamento}

As autoras agradecem à Fundação de Amparo à Ciência e Tecnologia de Pernambuco pelo apoio financeiro.

\section{Conflito de Interesses}

As autoras informaram que não há conflito de interesses.

\section{Direitos Autorais}

A RAC detém os direitos autorais deste conteúdo.

\section{Contribuições dos Autores}

$1^{2}$ autora: conceitualizaçáo (igual); curadoria de dados (líder); análise formal (líder); investigação (líder); metodologia (líder); visualização (igual); validação (líder); redação rascunho original (igual); redação - revisão e edição (igual). $2^{a}$ autora: conceitualização (igual); validação (de apoio); administração do projeto (líder); redação - rascunho original (igual); redação - revisão e edição (igual); metodologia (de apoio); visualização (igual); aquisição de financiamento (líder).

$3^{a}$ autora: conceitualização (igual); investigação (de apoio); administração do projeto (de apoio); supervisão (líder); redação - rascunho original (igual); redação - revisão e ediçăo (igual); visualização (igual).

\section{Verificação de Plágio}

A RAC mantém a prática de submeter todos os documentos aprovados para publicação à verificação de plágio, mediante o emprego de ferramentas específicas, e.g.: iThenticate.

\section{Método de Revisão por Pares}

Este conteúdo foi avaliado utilizando o processo de revisão por pares duplo-cego (double-blind peer-review). A divulgação das informaçóes dos pareceristas constantes na primeira página e do Relatório de Revisão por Pares (Peer Review Report) é feita somente após a conclusão do processo avaliativo, e com o consentimento voluntário dos respectivos pareceristas e autores.

\section{Disponibilidade dos Dados}

Todos os dados e materiais foram disponibilizados publicamente por meio da plataforma Harvard Dataverse e podem ser acessados em:

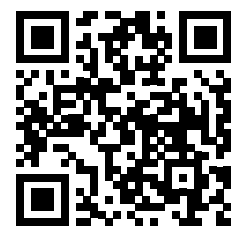

Renata Braga Berenguer de Vasconcelos; Joséte Florencio dos Santos; Jackeline Amantino de Andrade, 2020, "Replication Data for: Innovation in micro and small enterprises: Resources and capabilities", https://doi.org/10.7910/DVN/TODLHW, Harvard Dataverse, V1. 